\title{
Airport Pavement Preservation Planning applying Numerical Model to forecast Pavement Condition
}

\author{
Karen A. Camarena, Eng. ${ }^{1}$, Leonardo Flores, M.Sc. ${ }^{1}$, Edward Santa Maria, M.Sc. ${ }^{1}$, Jose A. Flores, Dr. ${ }^{1}$, Freddy C. \\ Tineo, Dr. ${ }^{1}$ \\ 1'Universidad Nacional de Ingeniería, Perú, kacamarenac@uni.pe, 1floresg@uni.edu.pe, edsantad@hotmail.com, \\ jflores@uni.edu.pe,ftineo@uni.edu.pe
}

\begin{abstract}
This article presents the application of a numerical model aimed to develop a pavement preservation program.

Given the limitation of data that seize and report pavement improvements after the perform of preservation treatments, for this work we will continue with the example to which was calibrated the model, considering that we have collected its historical background and we know its Pavement Condition Index (PCI) before and after several interventions.

Finally, the analysis of alternatives to preserve pavement condition above the minimum acceptable is presented, showing the benefits in the quality of the infrastructure (service level) and the allocation of budget during its lifecycle. $M \& \boldsymbol{R}$.

Keywords --Pavement, PCI, numerical model, pavement age,
\end{abstract}

\section{INTRODUCTION}

Maintenance of airport pavements must be carried out in a preventive and programmed way, instead based on immediate needs and without proper planning [8], jeopardizing operational safety and without considering the economic resources available.

Pavement Deterioration forecasting is needed in order to analyze different pavement interventions alternatives and develop an optimum multi-year maintenance and rehabilitation (M\&R) plan [8]. In this regard, the Prediction Numerical Model plays an important, essential role, as is shown in

Fig. 1.

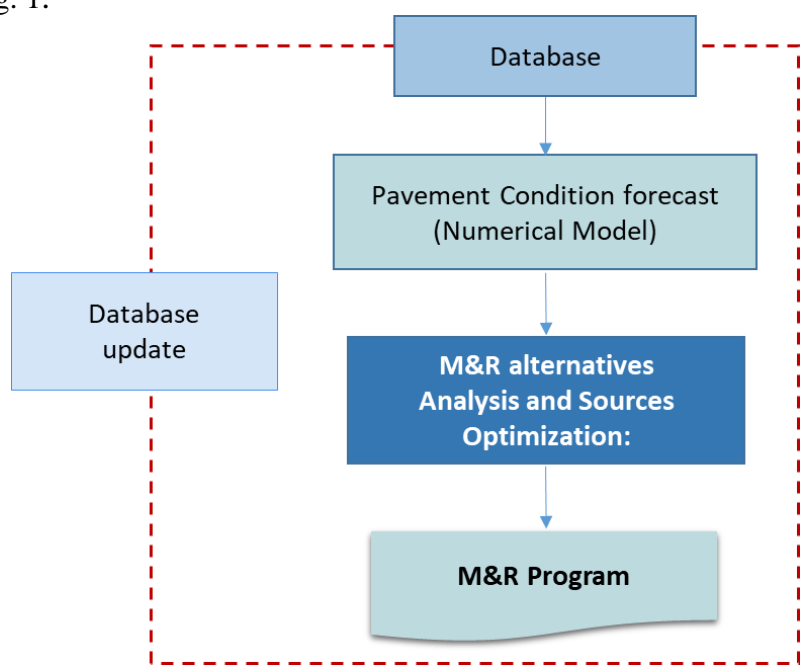

Fig. 1. Airport Pavement Management System (APMS)

Digital Object Identifier (DOI):

http://dx.doi.org/10.18687/LACCEI2019.1.1.87

ISBN: 978-0-9993443-6-1 ISSN: 2414-6390

\section{A. Pavement Condition}

The pavement condition data is a fundamental component of an APMS and requires an objective, systematic and repetitive evaluation process [8]. The ASTM D5340, qualify the pavement condition with the PCI, whose value corresponds between 0 and 100, see TABLE 1 . The mentioned standard stablish that a pavement begins its life cycle with perfect conditions $(\mathrm{PCI}=100)$ and after being subjected to service cycles, that cause pavement deterioration can reach a collapsed state $(\mathrm{PCI}=0)[1]$.

\begin{tabular}{|c|c|c|}
\hline \multicolumn{3}{|c|}{ PCI rating scale } \\
\hline 86 & -100 & GOOD \\
\hline 71 & -85 & SATISFACTORY \\
\hline 56 & -70 & ACCEPTABLE \\
\hline 41 & -55 & POOR \\
\hline 26 & -40 & VERY POOR \\
\hline 11 & -25 & SERIOUS \\
\hline 0 & -10 & FAILED \\
\hline
\end{tabular}

\section{B. Numerical Model to forecast Pavement Condition}

The deterioration models are relative to the influence of the pavements condition indicators, as Pavement Condition Index (PCI), and are used to predict when pavement maintenance will be required in order to ensure operational safety [8].

The pavement preservation planning is not a static process; therefore, is based on probability as a tool to determine the future pavement condition [19].

\section{Maintenance And Rehabilitation (M\&R) Policy}

The M\&R policy consist on identifying any possible failure that can occur on airport pavements, as well as, the repair and maintenance methodology currently used to these problems (with its according cost) and the optimum and acceptable service level of the assess pavement. All these aimed to contribute with the making decisions criteria of M\&R programming [8]. 
There is a range where pavement's deterioration drop dramatically in a short time of its lifecycle, then, it is logical to say that interventions on pavements when these report greater deterioration are more expensive than when the condition of pavements is optimum or acceptable [10]. The Fig. 2 illustrates what is mentioned before.

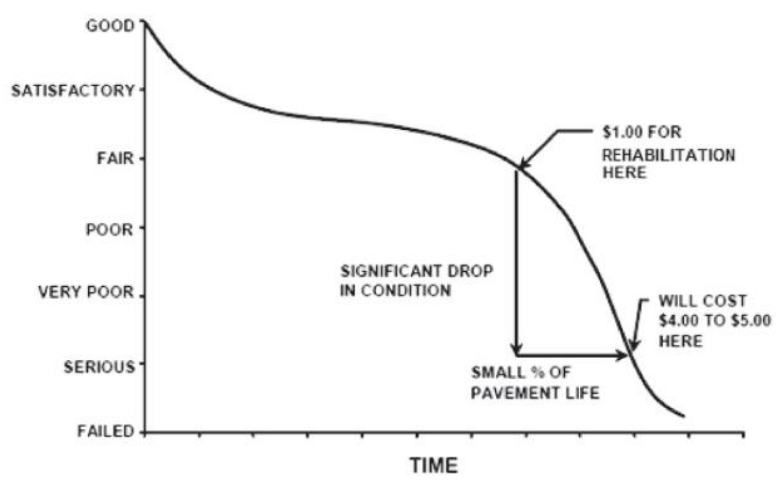

Fig. 2. Typical pavement condition lifecycle SOURCE: [10]

\section{A. Pavement Preservation Treatments}

Below the pavement preservation treatments are described and TABLE 2 relates PCI classification of ASTM D5340 with its applicable treatments.

i. Preventive Maintenance:

It is a programmed work that is carrying out with the aim to delay the significant drop in pavement condition or any possible pavement efficiency reduction[10].

\section{ii. Corrective Maintenance:}

Is defined as maintenance activities performed after pavement defects occur with the aim to correct it immediately [12]. Corrective maintenance is less desirable than the preventive one, since let pavements' defects occur could jeopardize aircrafts' operational safety.

iii. Rehabilitation:

A strategy performed to restore pavement to its original condition. This treatment is generally done before the drop from poor to serious to avoid costly reconstruction work [12].

iv. Reconstruction:

Total replacement of the existent pavement structure.
TABLE 2. PCI AND APPLICABLE TREATMENTS SOURCE: [12]

\begin{tabular}{|c|c|c|}
\hline PCI Rating & Description & $\begin{array}{c}\text { Applicable Pavement Preservation } \\
\text { Treatments } \\
\end{array}$ \\
\hline $86-100$ & Good—only minor distresses & Routine maintenance only \\
\hline $71-85$ & Satisfactory_low and medium distresses & Preventive maintenance \\
\hline $56-70$ & Fair, some distresses are severe & $\begin{array}{l}\text { Corrective maintenance and } \\
\text { rehabilitation }\end{array}$ \\
\hline $41-55$ & $\begin{array}{l}\text { Poor-severity of some of the distresses can } \\
\text { cause operational problems }\end{array}$ & Rehabilitation or reconstruction \\
\hline $26-40$ & $\begin{array}{l}\text { Very poor-severe distresses cause } \\
\text { operational problems. }\end{array}$ & Rehabilitation and reconstruction \\
\hline $11-25$ & $\begin{array}{l}\text { Serious-many severe distresses cause } \\
\text { operational restrictions }\end{array}$ & Immediate repairs and reconstruction \\
\hline $0-10$ & $\begin{array}{l}\text { Failed_pavement deterioration prevents safe } \\
\text { aircraft operations }\end{array}$ & Reconstruction \\
\hline
\end{tabular}

\section{B. Pavement's Level of Service}

There are several types of level of service that may be used to establish the amount of maintenance and rehabilitation airport pavements may require [12], and TABLE 3 describe levels of service for medium-size airport aim to the pavement case assessed.

TABLE 3. EXAMPLE LEVELS OF SERVICE FOR A MEDIUM-SIZE AIRPORT WITH AC PAVEMENTS SOURCE: [12]

\begin{tabular}{lccc}
\hline & \multicolumn{2}{c}{$\begin{array}{c}\text { Level of Service } \\
\text { Facility Type }\end{array}$} & $\begin{array}{c}\text { Minimum Acceptable Level of } \\
\text { Service }\end{array}$ \\
\cline { 2 - 3 } & Target or desirable & Minimum acceptable & PCI for Individual Sections \\
\hline Runway & 80 & 65 & 55 \\
Taxiway & 70 & 60 & 45 \\
Apron & 70 & 60 & 40 \\
\hline
\end{tabular}

III. NUMERICAL MODEL TO FORECAST PAVEMENT CONDITION (APPLICATION)

The numerical model to be applied at this article was calibrated to the runway of Cajamarca Airport (Peru) and its development and validation is described in document [4].

Following is a summary of inputs and the numerical model obtained:

\section{A. Input: Data of Cajamarca Airport runway}

- Pavement condition history:

TABLE 4. PCI INSPECTIONS AND M\&R HISTORY SOURCE: [6]

\begin{tabular}{|c|c|c|}
\hline Year & Activity & PCI \\
\hline 2003 & Pavement Improvement and expansion & -- \\
2007 & Pavement condition inspection & 91 \\
2013 & Pavement condition inspection & 65 \\
2014 & Corrective maintenance & -- \\
2014 & Pavement condition inspection & 86 \\
2015 & Pavement condition inspection & 82 \\
\hline
\end{tabular}

$17^{\text {th }}$ LACCEI International Multi-Conference for Engineering, Education, and Technology: "Industry, Innovation, And Infrastructure for Sustainable Cities and Communities", 24-26 July 2019, Jamaica. 


\section{- Pavement structure}

The runway $\mathrm{PCN}$ is $45 / \mathrm{F} / \mathrm{D} / \mathrm{X} / \mathrm{T}$ and the maximum allowable aircraft type is the Boeing 737 (maximum takeoff weight = $134000 \mathrm{lb})$.

- $\quad$ Traffic Data

TABle 5. OPERATIONS ProJeCtion 2018-2034 SOURCE: [6]

\begin{tabular}{|c|c|c|}
\hline Year & $\begin{array}{c}\mathbf{N}^{\circ} \text { annual average } \\
\text { operations }\end{array}$ & $\begin{array}{c}\mathbf{N}^{\circ} \text { annual average } \\
\text { departures }\end{array}$ \\
\hline 2018 & 4542 & 2271 \\
\hline 2019 & 4860 & 2430 \\
\hline 2020 & 5201 & 2601 \\
\hline 2021 & 5565 & 2783 \\
\hline 2022 & 5943 & 2972 \\
\hline 2023 & 6335 & 3168 \\
\hline 2024 & 6741 & 3371 \\
\hline 2025 & 7159 & 3580 \\
\hline 2026 & 7588 & 3794 \\
\hline 2027 & 8021 & 4011 \\
\hline 2028 & 8454 & 4227 \\
\hline 2029 & 8894 & 4447 \\
\hline 2030 & 9320 & 4660 \\
\hline 2031 & 9740 & 4870 \\
\hline 2032 & 10139 & 5070 \\
\hline 2033 & 10535 & 5268 \\
\hline 2034 & 10945 & 5473 \\
\hline
\end{tabular}

B. Output: Numerical model calibrated to Cajamarca Airport runway

This model consists of Markov Chains which were calibrated with the Logistic Regression of historical data.

A pavement begins its life cycle in almost perfect conditions and is then subjected to service cycles that cause deterioration of the pavement condition. The extrapolation of the Markov process curve represents the future pavement behavior and allows a dynamic programming, to produce $M \& R$ optimal strategies [3].

For the development of this model, the Markov process states correspond to different pavement deterioration levels defined in the PCI qualification. The PCI range (from 0 to 100) is divided into ten "states" of 10 interval points, as illustrated in the Table 6.

Table 6. PAVEMENT CONDITION - MARKOV PROCESS. SOURCE:[3]

\begin{tabular}{|l|ccccccccccc|}
\hline Condition & A & B & C & D & E & F & G & H & I & J \\
\hline PCI Range & $100-91$ & $90-81$ & $80-71$ & $70-61$ & $60-51$ & $50-41$ & $40-31$ & $30-21$ & $20--11$ & $10-0$ \\
\hline
\end{tabular}

Equation (1) illustrates the state vector for a given service cycle.

State vector $(\bar{E})$ for service cycle "i":

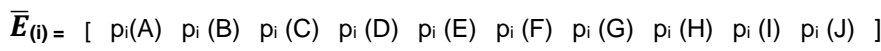

Where, $\operatorname{pi}(\mathrm{X})$ is the probability that pavement is in the condition "X" in the service cycle "i", the "state vector" $\left(\overline{\boldsymbol{E}}_{(\mathbf{i})}\right)$ indicates the probability that a pavement section is in each of the ten states in a year of service (i) and a "service cycle" lasts for one year, at which time the pavement is subjected to a determined climate and traffic.

In the pavements management it is assumed that all sections of the pavement are in the "A" state (PCI of 90 to 100) at the age of zero years (service cycle "0"), resulting a state vector [16]:

$$
\overline{\boldsymbol{E}}_{(\mathbf{0})=}\left[\begin{array}{lllllllllll} 
& 1 & 0 & 0 & 0 & 0 & 0 & 0 & 0 & 0 & 0
\end{array}\right]
$$

To model the way pavement deteriorates over time, it is necessary to identify the transition probability matrix (TPM). It is assumed that the pavement condition cannot fall more than one state (10 points) during a service cycle. In addition, the pavement may remain in its condition or deteriorate and move to the next state in one year. Consequently, the TPM has the following form:

$\overline{\mathbf{P}}=\left[\begin{array}{cccccccccc}81 \% & 19 \% & 0 & 0 & 0 & 0 & 0 & 0 & 0 & 0 \\ 0 & 71 \% & 29 \% & 0 & 0 & 0 & 0 & 0 & 0 & 0 \\ 0 & 0 & 56 \% & 44 \% & 0 & 0 & 0 & 0 & 0 & 0 \\ 0 & 0 & 0 & 37 \% & 63 \% & 0 & 0 & 0 & 0 & 0 \\ 0 & 0 & 0 & 0 & 5 \% & 95 \% & 0 & 0 & 0 & 0 \\ 0 & 0 & 0 & 0 & 0 & 0 \% & 100 \% & 0 & 0 & 0 \\ 0 & 0 & 0 & 0 & 0 & 0 & 0 \% & 100 \% & 0 & 0 \\ 0 & 0 & 0 & 0 & 0 & 0 & 0 & 0 \% & 100 \% & 0 \\ 0 & 0 & 0 & 0 & 0 & 0 & 0 & 0 & 0 \% & 100 \% \\ 0 & 0 & 0 & 0 & 0 & 0 & 0 & 0 & 0 & 100 \%\end{array}\right]$

The state vector for any year of service is obtained by multiplying the initial state vector by the TPM, as illustrated in (4).

$$
\begin{aligned}
& \overline{\boldsymbol{E}}_{(1)}=\overline{\boldsymbol{E}}_{(0)} \times \overline{\mathbf{P}} \\
& \overline{\boldsymbol{E}}_{(2)}=\overline{\boldsymbol{E}}_{(1) \times} \times \overline{\mathbf{P}}=\overline{\boldsymbol{E}}_{(0) \times} \times \overline{\mathbf{P}}^{2} \\
& \cdot \\
& \overline{\boldsymbol{E}}_{(\mathrm{t})}=\overline{\boldsymbol{E}}_{(\mathrm{t}-1) \times} \overline{\mathbf{P}}=\overline{\boldsymbol{E}}_{(0)} \times \overline{\mathbf{P}}^{\mathrm{t}}
\end{aligned}
$$

With this process, if the transition matrix can be estimated, the pavement status for any service cycle can be predicted. The TPM can be determined based on expert criteria or historical data if available, through non-linear regression, where the objective is to minimize the difference between the PCI obtained as a function of time (product of the regression) and 
the value predicted (using the Markov chain) for a given service cycle [3].

Replacing (2) and (3) in (4), table 8 is obtained:

Table 7. NUMERICAL MODEL STATE VECTORS AND PCI

\begin{tabular}{|c|c|c|c|c|c|c|c|c|c|c|c|}
\hline \multirow{2}{*}{$\begin{array}{c}\text { Age } \\
(\text { years })\end{array}$} & \multicolumn{10}{|c|}{ State vector $(\%)$} & \multirow{2}{*}{ PCI } \\
\hline & $\mathbf{A}$ & B & $\mathbf{C}$ & D & $\mathbf{E}$ & $\mathbf{F}$ & $\mathbf{G}$ & $\mathbf{H}$ & I & $\mathbf{J}$ & \\
\hline 0 & 100.0 & 0.0 & 0.0 & 0.0 & 0.0 & 0.0 & 0.0 & 0.0 & 0.0 & 0.0 & 100 \\
\hline 1 & 81.3 & 18.7 & 0.0 & 0.0 & 0.0 & 0.0 & 0.0 & 0.0 & 0.0 & 0.0 & 98 \\
\hline 2 & 66.1 & 28.4 & 5.5 & 0.0 & 0.0 & 0.0 & 0.0 & 0.0 & 0.0 & 0.0 & 96 \\
\hline 3 & 53.7 & 32.4 & 11.4 & 2.4 & 0.0 & 0.0 & 0.0 & 0.0 & 0.0 & 0.0 & 94 \\
\hline 4 & 43.7 & 33.0 & 15.9 & 6.0 & 1.5 & 0.0 & 0.0 & 0.0 & 0.0 & 0.0 & 91 \\
\hline 5 & 35.5 & 31.5 & 18.5 & 9.3 & 3.8 & 1.4 & 0.0 & 0.0 & 0.0 & 0.0 & 88 \\
\hline 6 & 28.9 & 28.9 & 19.5 & 11.7 & 6.0 & 3.6 & 1.4 & 0.0 & 0.0 & 0.0 & 85 \\
\hline 7 & 23.5 & 25.8 & 19.3 & 13.0 & 7.6 & 5.7 & 3.6 & 1.4 & 0.0 & 0.0 & 81 \\
\hline 8 & 19.1 & 22.6 & 18.3 & 13.4 & 8.6 & 7.2 & 5.7 & 3.6 & 1.4 & 0.0 & 76 \\
\hline 9 & 15.5 & 19.6 & 16.8 & 13.1 & 8.9 & 8.1 & 7.2 & 5.7 & 3.6 & 1.4 & 71 \\
\hline 10 & 12.6 & 16.7 & 15.1 & 12.4 & 8.7 & 8.4 & 8.1 & 7.2 & 5.7 & 5.1 & 65 \\
\hline 11 & 10.3 & 14.2 & 13.3 & 11.3 & 8.2 & 8.2 & 8.4 & 8.1 & 7.2 & 10.7 & 59 \\
\hline 12 & 8.3 & 11.9 & 11.6 & 10.1 & 7.5 & 7.8 & 8.2 & 8.4 & 8.1 & 18.0 & 53 \\
\hline 13 & 6.8 & 10.0 & 9.9 & 8.9 & 6.7 & 7.1 & 7.8 & 8.3 & 8.4 & 26.1 & 47 \\
\hline 14 & 5.5 & 8.3 & 8.5 & 7.7 & 5.9 & 6.4 & 7.1 & 7.8 & 8.2 & 34.5 & 42 \\
\hline 15 & 4.5 & 6.9 & 7.1 & 6.6 & 5.2 & 5.6 & 6.4 & 7.2 & 7.8 & 42.7 & 37 \\
\hline 16 & 3.6 & 5.7 & 6.0 & 5.6 & 4.4 & 4.9 & 5.6 & 6.4 & 7.1 & 50.5 & 33 \\
\hline 17 & 3.0 & 4.7 & 5.0 & 4.8 & 3.8 & 4.2 & 4.9 & 5.6 & 6.4 & 57.6 & 30 \\
\hline 18 & 2.4 & 3.9 & 4.2 & 4.0 & 3.2 & 3.6 & 4.2 & 4.9 & 5.6 & 64.0 & 26 \\
\hline 19 & 2.0 & 3.2 & 3.5 & 3.3 & 2.7 & 3.0 & 3.6 & 4.2 & 4.9 & 69.7 & 24 \\
\hline 20 & 1.6 & 2.6 & 2.9 & 2.8 & 2.2 & 2.5 & 3.0 & 3.6 & 4.2 & 74.5 & 21 \\
\hline
\end{tabular}

With Table 7 data (Age and PCI), it is presented the quantitative numerical model graph that represents the pavement behavior with characteristics and similar conditions to the Cajamarca Airport runway (Fig. 3), where the PCI range for its state is shown in Table 6.

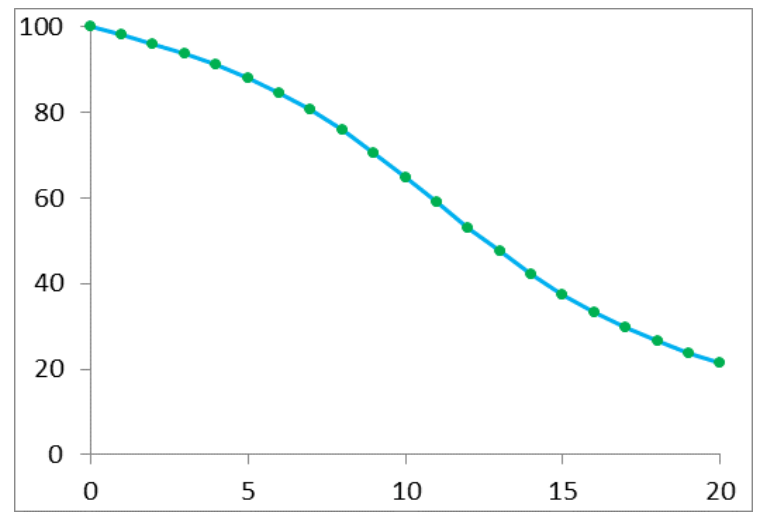

Fig. 3. PCI vs Age - Numerical model state vectors and PCI

\section{COST OF APPLICABLE TREATMENTS FOR AIRPORT PAVEMENTS}

To illustrate the costs of different treatments and how it varies with pavement deterioration, several data was taken from different projects for pavements (in Peru) with similar features, obtaining the results shown in TABLE 8 and Fig. 4

TABle 8. Cost OF PAVEMENTS TREATMENTS IN PERU SOURCE: [6] , [12]

\begin{tabular}{|c|c|c|c|}
\hline \multicolumn{2}{|c|}{ CALIFICACIÓN PCI } & $\begin{array}{c}\text { APPLICABLE } \\
\text { TREATMENTS }\end{array}$ & $\begin{array}{c}\text { COST } \\
(\$ / m 2)\end{array}$ \\
\hline $86-100$ & GOOD & $\begin{array}{c}\text { Preventive } \\
\text { maintenance (routine) }\end{array}$ & 7 \\
\hline $71-85$ & SATISFACTORY & $\begin{array}{c}\text { Preventive } \\
\text { maintenance }\end{array}$ & 14 \\
\hline $56-70$ & ACCEPTABLE & Corrective maintenance & 29 \\
\hline $41-55$ & POOR & Rehabilitation & 65 \\
\hline $26-40$ & VERY POOR & $\begin{array}{c}\text { Rehabilitation or } \\
\text { reconstruction }\end{array}$ & 110 \\
\hline $11-25$ & SERIOUS & $\begin{array}{c}\text { Immediate repairs and } \\
\text { reconstruction }\end{array}$ & 161 \\
\hline $0-10$ & FAILED & $\begin{array}{c}\text { Reconstruction } \\
161\end{array}$ \\
\hline
\end{tabular}

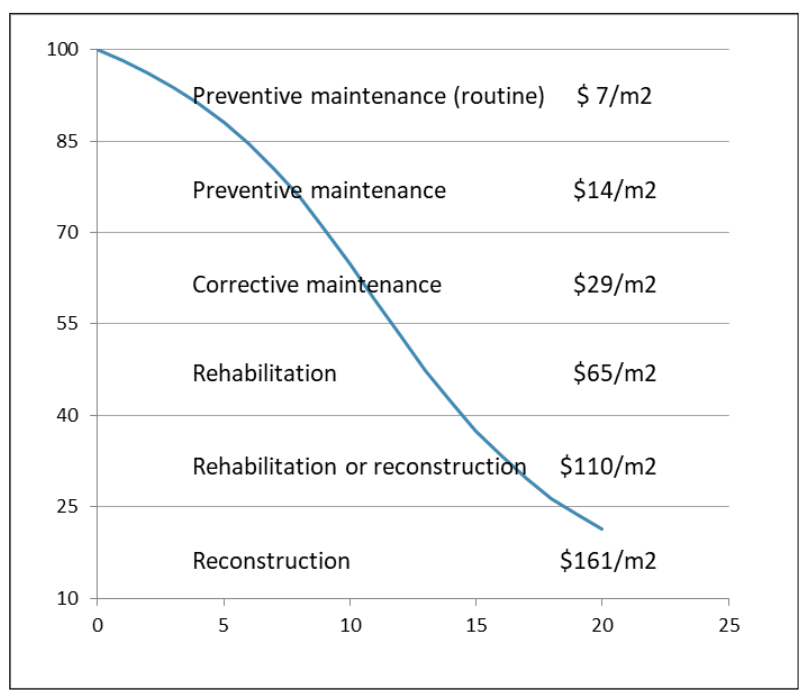

Fig. 4. PCI vs Age $-\mathrm{M} \& \mathrm{R}$ related costs

\section{ANALYSIS OF FUTURE PAVEMENT CONDITION}

The analysis below is based on the numerical model calibrated for Cajamarca airport pavement. It is important to mention that evaluating how many PCI points get up the pavement condition with an intervention is not part of this investigation, then, is a limitation.

$17^{\text {th }}$ LACCEI International Multi-Conference for Engineering, Education, and Technology: "Industry, Innovation, And Infrastructure for Sustainable Cities and Communities”, 24-26 July 2019, Jamaica. 
For the following cases, the amount of PCI points that pavement recover with a $M \& R$ intervention is based on results of M\&R pavement history of Cajamarca airport.

\section{A. Future condition without maintenance:}

The Fig. 5 shows the 'hypothetic' case where no maintenance interventions are performed on the pavement along its life cycle (20 years). When the pavement life is over, it is assumed that rehabilitation or reconstruction is performed, thus, the PCI is 100 again.

The pavement condition is analyzed until the year 30 to be compared with the cases with maintenance interventions.

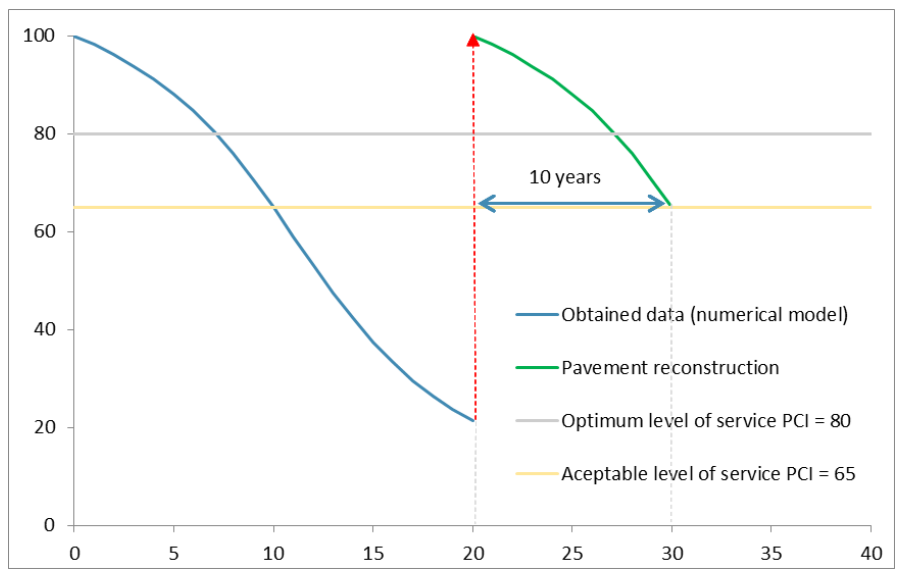

Fig. 5. PCI vs Age - Without M\&R

\section{B. Future condition with Corrective Maintenance}

The Fig. 6 shows the case where corrective maintenance interventions are performed when the pavement condition drop below the acceptable level of service $(\mathrm{PCI}=65)$. For this example, as we have data of the pavement (Cajamarca Airport) before and after corrective maintenance is performed, we have a notion of the PCI number after these interventions $(\mathrm{PCI}=86)$.

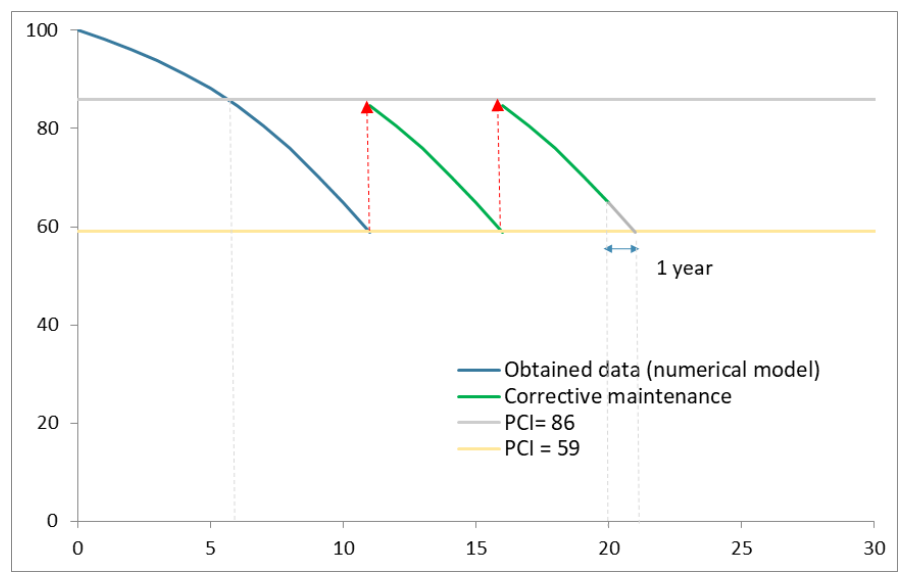

Fig. 6. PCI vs Age - With Corrective Maintenance

\section{Future condition with Preventive Maintenance}

The Fig. 7 shows the case where preventive maintenance interventions are performed when the pavement condition narrows the acceptable level of service $(\mathrm{PCI}=65)$. It is important to mention that, we do not have real data about PCI number after preventive maintenance because on the pavement of study (Cajamarca Airport) these have not been performed. To overcome these situation and continue with the purposes of this work, conservatively, we will assume a $\mathrm{PCI}=85$ (the minimum) after a preventive maintenance intervention, since we now that these interventions must be design in order to reach a PCI number equal or above the optimum level of service $(\mathrm{PCI}=85)$.

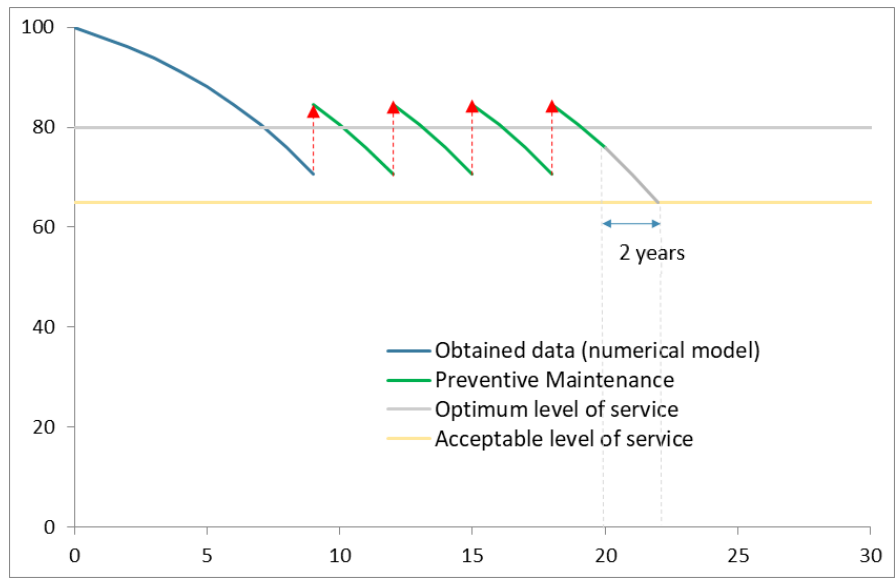

Fig. 7. PCI vs Age - With Preventive Maintenance

\section{EVALUATION OF ALTERNATIVES}

To evaluate the M\&R alternatives, it is assumed that the analysis is performed at the beginning of the life-cycle of the pavement.

\section{A. Without maintenance:}

Is not considered as alternative, because it jeopardizes the operational safety of aircrafts during the time with PCI below the minimum acceptable $(\mathrm{PCI}=65)$.

\section{B. Alternative with Corrective Maintenance}

Corrective maintenance is performed when PCI drop below the minimum acceptable $(\mathrm{PCI}=65)$ and, in order to this situation, the operational safety could be threatened the time with the PCI below that mark, no matter how short this period could be. On the other hand, it is not the best option when allocating resources as it can be seen in Fig. 9.

$17^{\text {th }}$ LACCEI International Multi-Conference for Engineering, Education, and Technology: "Industry, Innovation, And Infrastructure for Sustainable Cities and Communities", 24-26 July 2019, Jamaica. 


\section{Alternative with Preventive Maintenance}

\section{Selected alternative.}

This alternative ensures operational safety and optimizes economic resources during the life-cycle of the pavement as can be seen in Fig. 8 and Fig. 9.

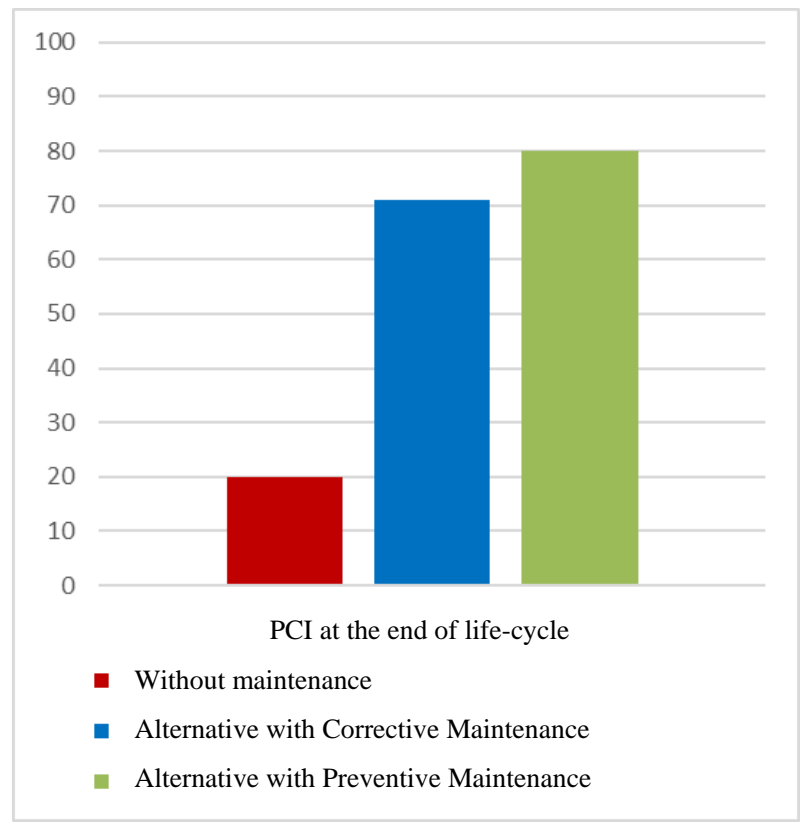

Fig. 8. Analysis of alternatives - Level of service

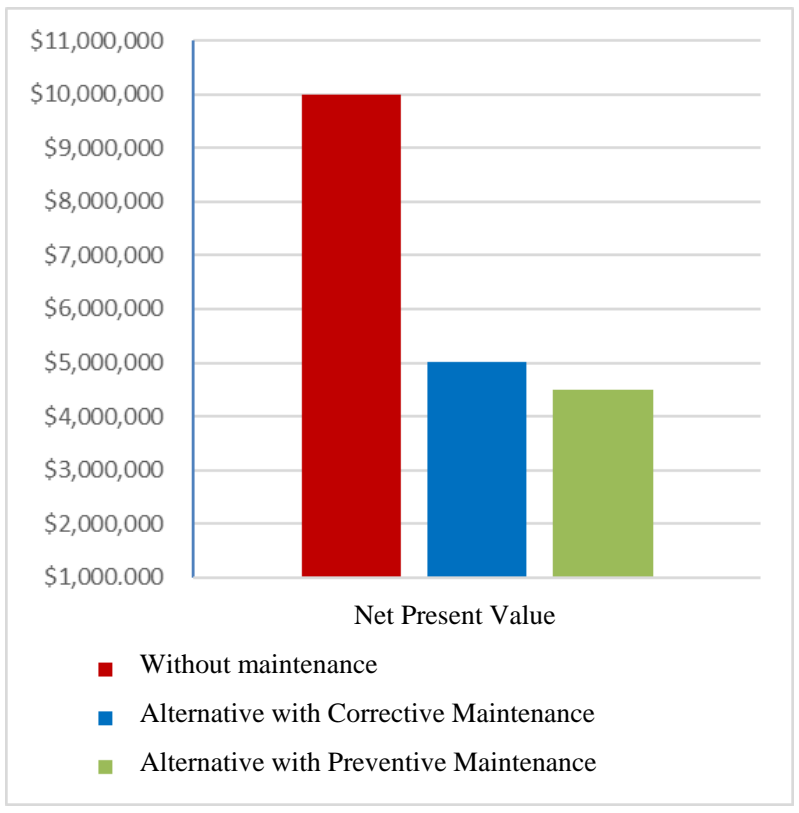

Fig. 9. Analysis of alternatives - Costs

\section{CONCLUSIONS}

1. If deterioration models are calibrated, for different circumstances (weather, traffic, material, among others), under which the Peruvian airport pavements are in service; the pavement condition prognosis will depend on how the pavement behaves at present (know the current state).

2. The associated costs for different strategies of M\&R vary dramatically comparing interventions performed when pavement condition is satisfactory against a serious or failure condition, that jeopardize operational safety. This difference is shown in Fig. 4 and Fig. 8. In this regard, it is concluded that programming preventive maintenance ensure operational safety optimizing economic resources.

3. To perform maintenance activities based on immediate necessities (corrective maintenance) and without a correct planification, as the assessed case (Cajamarca airport), result in an inefficient management resources, since, it does not take into account the cost-benefit relation during the pavement lifecycle. This comparison is shown in Fig. 8 .

\section{REFERENCES}

[1] American Society for Testing and Materials, "Standard Test Method for Airport Pavement Condition Index Surveys", ASTM D5340-12, Pensilvania, 2013.

[2] Butt Abbas, Shahin Mohamed, Feighan Kieran y Carpenter Samuel, "Pavement Performance Prediction Model Using the Markov Process", Transportation Research Record 1123, Illinois, 1987.

[3] Butt Abbas, Shahin Mohamed, Carpenter Samuel y Carnahan James, "Application of Markov Process to Pavement Management Systems at Network Level", 3rd International Conference on Managing Pavements, Illinois, 1994.

[4] Camarena Karen, Flores Leonardo, "Proposal of Numerical Model for Airport Pavement Management Purposes", 16th LACCEI International Multi-Conference for Engineering, Education, and Technology; Lima, Perú, 2018.

[5] Devore Jay, "Probabilidad y estadística para ingeniería y ciencias", Sexta edición, Thomson Editores, México, 2005.

[6] Dirección General de Aeronáutica Civil (DGAC), Ministerio de Transportes y Comunicaciones (MTC), Solicitud de acceso a la información pública T-269907-2017, Lima, Perú, 2017.

[7] Federal Aviation Administration - U.S. Department of Transportation, "Airport Pavement Design and Evaluation", Advisory Circular No 150/5320-6E, Washington D.C., 2009.

[8] Federal Aviation Administration - U.S. Department of Transportation, "Airport Pavement Management Program (PMP)", Advisory Circular No 150/5380-7B, Washington D.C., 2014.

[9] Federal Aviation Administration - U.S. Department of Transportation, "Guidelines and Procedures for Maintenance of Airport Pavements", Advisory Circular No 150/5380-6C, Washington D.C., 2014.

$17^{\text {th }}$ LACCEI International Multi-Conference for Engineering, Education, and Technology: "Industry, Innovation, And 
[10]Freeman Thomas, Borowiec Jeffrey, Wilson Bryan, Arabali Poura y Sakhaeifar Maryam, "Pavement Maintenance Guidelines for General Aviation Airport Management", Airport Cooperative Research Program Report 159, Washington D.C., 2016.

[11]George K.P., Rajagopal A.S. y Lim L.K., "Models for Predicting Pavement Deterioration", Transportation Research Record 1215, Misisipi, 1989.

[12]Hajek Jerry, Hall Jim y Hein David, "Common Airport Pavement Maintenance Practices", Airport Cooperative Research Program Synthesis 22, Washington D.C., 2011.

[13]Nuñez María y Shahin Mohamed, "Pavement Condition Data Analysis and Modeling”, Transportation Research Record 1070, Illinois, 1986.

[14]Pellinen Terhi, Witczak Matthew, y Bonaquist Ramon, "Asphalt Mix Master Curve Construction using Sigmoidal Fitting Function with NonLinear Least Squares Optimization Technique", Materials characterization/modeling of pavement systems ASCE, New York, 2003.

[15]Solminihac Hernan, "Gestión de infraestructura vial", Ediciones Universidad Católica de Chile, Chile, 2001.

[16]Solorio José, Márquez Zaydith, Montoya Monserrat, Cárdenas Santa y Hernández Domínguez, "Aplicación de métodos markovianos en el modelado del deterioro de carreteras", Instituto Méxicano del Transporte, Publicación Técnica N³96, México, 2014.

[17]Tighe Susan y Covalt Margaret, "Implementation of an airport Pavement Management System", Transportation Research Circular, E-C127, Washington D.C., 2008.

[18]Yusoff Nur, Chailleux Emmanuel y Airey Gordon, “A Comparative Study of the Influence of Shift Factor Equations on Master Curve Construction", International Journal of Pavement Research and Technology, Vol. $4 \mathrm{~N}^{\circ} 6$, Nottingham, 2011.

[19]Zimmerman Kathryn, "Pavement Managment Methodologies to select Projects and Recommend Preservation Treatments", Synthesis of Highway Practice 222, Washington D.C., 1995.

$17^{\text {th }}$ LACCEI International Multi-Conference for Engineering, Education, and Technology: "Industry, Innovation, And Infrastructure for Sustainable Cities and Communities", 24-26 July 2019, Jamaica. 